\title{
The Agriculture-Nutrition-Income Nexus in Tonga: Is Postharvest Loss Undermining Horticulture Market Efficiency in Tonga?
}

\author{
Steven J. R. Underhill ${ }^{1,2, *(\mathbb{D})}$, Soane Patolo ${ }^{3}$, Yuchan Zhou ${ }^{1}$ and Sarah Burkhart ${ }^{1(\mathbb{D})}$ \\ 1 Australian Centre for Pacific Islands Research, University of the Sunshine Coast, Sippy Downs Queensland \\ 4556, Australia; yzhou1@usc.edu.au (Y.Z.); sburkhar@usc.edu.au (S.B.) \\ 2 Department of Crop Production, College of Agriculture, Fisheries and Forestry, Fiji National University, \\ Nausori, Suva, Fiji \\ 3 MORDI Tonga Trust, Vaha'akolo Road, Haveluloto, Nuku'alofa P.O Box 996, Tonga; soanejr@morditonga.to \\ * Correspondence: Sunderhi@usc.edu.au; Tel.: +61-7-412140032
}

Received: 24 June 2020; Accepted: 15 September 2020; Published: 1 October 2020

\begin{abstract}
The Kingdom of Tonga has one of the highest rates of diet-related non-communicable diseases (NCDs) in the world. Initiatives to promote pro-health dietary behaviour are possibly being compromised by poor or inconsistent consumer accessibility to affordable and safe fresh fruits and vegetables, referred to as the agriculture-nutrition-income nexus. While donors increasingly focus on nutrition-sensitive agriculture across the Pacific, there is little contemporary information concerning Tonga's domestic horticultural distribution and market system, particularly in regards to food loss. This study surveyed 292 municipal and road-side vendors on Tongatapu and 'Utu Vava'u Islands, with the aim of mapping and analyzing horticultural markets and farm supply, transport logistics, and quantifying postharvest practice and market loss. Tonga's domestic horticultural market structure consists of a central municipal market and on Tongatapu Island, a supplementary network of urban and rural based road-side vendors. There is limited inter-island trade, with most farms located within $25 \mathrm{~km}$ of the central municipal market. Mean postharvest horticultural loss was very low, at $1.4 \%$ to $5.3 \%$, with road-side vendors more vulnerable to loss. This level of loss was thought to reflect short intra-island transport distance, the type of crops being traded, and rapid market throughput, rather than a level of value chain efficiency. Vendors regulated market supply volume and price discounting and were the principal strategies to mitigate postharvest loss. While low levels of postharvest loss, short transport logistics, and fast market throughput are consistent with a relatively efficient horticulture market system, vendor practice may be impeding fresh fruit and vegetable accessibility.
\end{abstract}

Keywords: pacific; agriculture; food security; non-communicable diseases

\section{Introduction}

The Kingdom of Tonga has one of the highest rates of diet-related non-communicable diseases (NCDs) in the world, with poor food choices and dietary behaviour as key contributors [1-3]. The incidence of type-two diabetes amongst the adult-age Tongan population has increased from $5.2 \%$ in 1973 to $19.0 \%$ in 2012 , and is anticipated to currently be approximately $22 \%$ [4], relative to a global diabetes prevalence rate of $8.8 \%$ [5]. Life expectancy in Tonga is in decline, primarily due to NCD-related mortalities [6]. In response, Tonga has introduced a plethora of initiatives and policies aimed at promoting healthy eating and lifestyle [7]. While such interventions have helped raise local community awareness, there has been limited and inconsistent formative dietary transition. One resistor to adopting pro-health dietary behaviour is that consumer accessibility to affordable and 
safe fresh fruits and vegetables in Tonga is often challenging. Tonga's domestic horticultural fresh food system has long been constrained by low horticultural productivity, limited access to arable land, little crop diversity and a high seasonality of product supply. While imported fresh fruits and vegetables can help offset inconsistencies in the local supply, imported products remain comparatively expensive, creating additional price-based disincentives to increased consumption [8,9].

Evans [1,2] was one of the first to highlight NCD-related community health implications associated with deficiencies in Tonga's horticultural food system. Recent reference to Tonga's agriculturenutrition-income nexus [3], nutrition-sensitive agriculture [10], and the inclusion of the horticulture enterprise development within Tonga's NCD strategy [7] reflects an increased appreciation of the close interconnectivity between horticultural-based food systems and NCD remediation. While donors have progressively focused on supporting nutrition-sensitive agriculture across the Pacific, there is surprisingly little contemporary information concerning Tonga's horticultural fresh food system. This is further complicated by the fact that Tonga's horticultural fresh food system is highly heterogeneous, being a composite of subsistence farming, communal sharing and commercial value chains that collectively exhibit a high degree of spatial and temporal variance $[8,11,12]$.

Household expenditure census data provides some insight, with consumers in Tonga becoming more reliant on commercial value chains to source their fresh fruits and vegetables [11,12]. A rapid proliferation in the level of private vehicle ownership in Tonga [12,13] is also likely to be transforming how and where local consumers commercially access fresh food. Tonga's central fruit and vegetable markets, which have long dominated the horticultural fresh food system [14], are being progressively supplemented by an expanding network of road-side vendors [8,9]. In the context of a local horticultural fresh food system in apparent transition, the horticultural value chains supporting these market have received little or no attention. Potential key risk factors within these value chains, such as postharvest handling practice, transport logistics, market storage conditions, and knowledge and capacity, are unclear. The level of horticultural postharvest loss, a possible indicator of market efficiency, has never been reported for Tonga. This lack of basic information on the structure and function of the horticultural market and distribution system in Tonga, potentially impedes the development of targeted interventions seeking to improve the enabling horticultural fresh food environment.

This study was undertaken to provide baseline information on Tonga's local horticultural fresh food system and the level of horticultural food loss to support future donor interventions aimed at enhancing consumer accessibility of locally grown fresh fruits and vegetables. The fruit and vegetable municipal markets and road-side vendors were spatially mapped, with transport logistics and postharvest handling practice documented. The level of postharvest loss per market type, possible loss contributors, and market vendor strategies to mitigate against postharvest food loss are further discussed.

\section{Materials and Methods}

\subsection{Location}

The Kingdom of Tonga is a Polynesian sovereign state located in the South Pacific consisting of 169 islands, of which 39 are inhabited, and has a total population of 100,650. This study was undertaken on two islands in the Tongan archipelago, the main island of Tongatapu and the northern Vava'u island group (Figure 1A). Tongatapu island has a land area of $260 \mathrm{~km}^{2}$ with $70 \%$ of Tonga's total population (Figure 1B). The island group of Vava'u, which is located $313 \mathrm{~km}$ north of Tongatapu, includes the main island of 'Utu Vava' $\mathrm{u}$, with a land area of $97 \mathrm{~km}^{2}$, and 40 close proximity smaller islands, and has approximately $15 \%$ of Tonga's total population [15] (Figure 1C). 


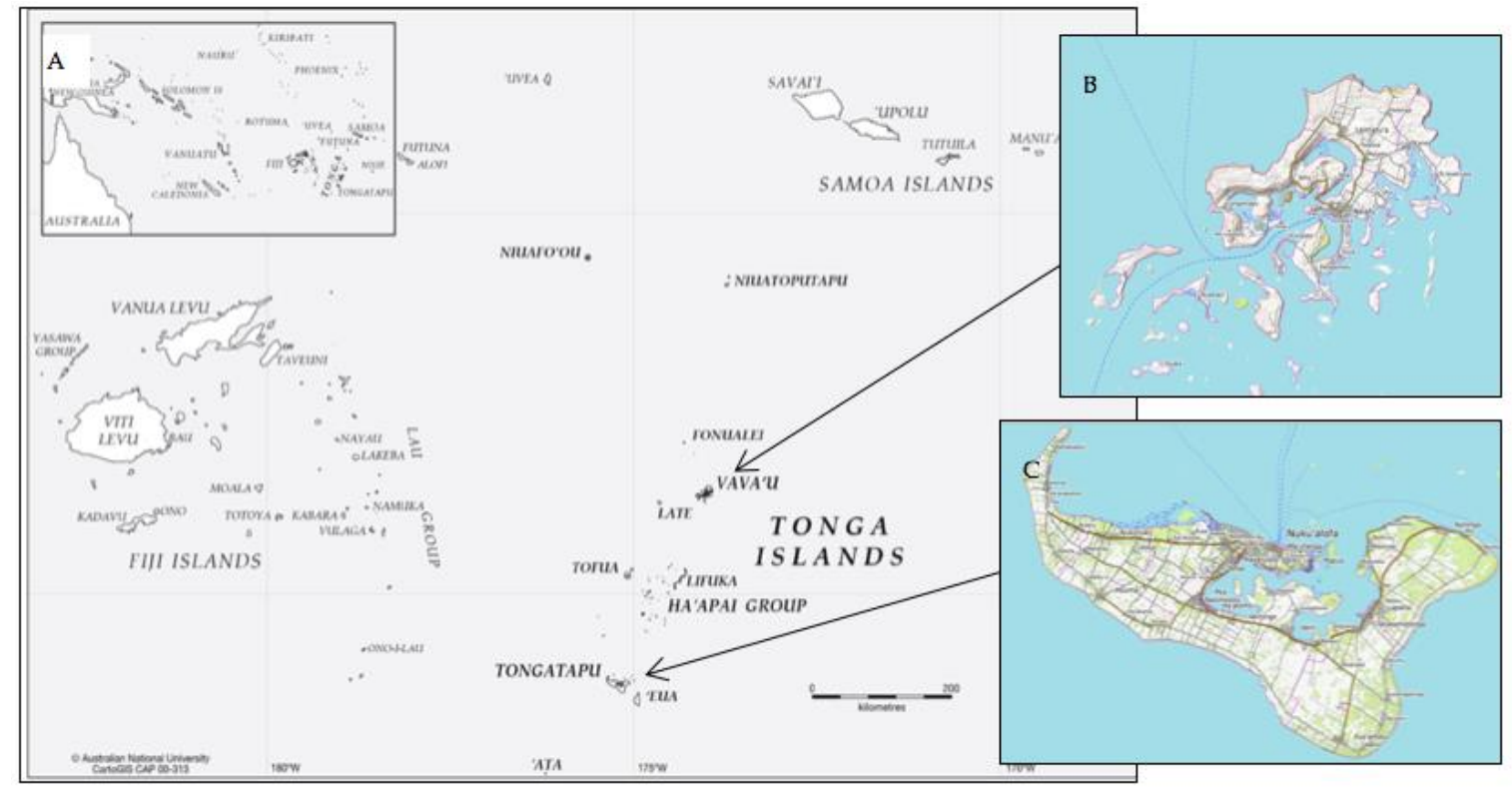

Figure 1. (A) Map of Tonga and the wider South Pacific region. (B) Map of Vava'u Island, Tonga. (C) Map of Tongatapu Island, Tonga. Map sources: (A) CartoGIS Services, College of Asia and the Pacific, The Australian National University 2019. (B,C) Opentopmap@).

\subsection{Markets Outlets Assessed}

This study focused on three types of fresh fruit and vegetable retail outlets: the municipal markets; road-side cluster markets (defined as being ten or more road-side vendors co-located within the same structure or building); and individual road-side market vendor stalls (including semi-permanent road-side structures, and temporary or mobile street stalls). Retail shops and supermarkets were excluded from this study. In Tonga, fruits and vegetables are primarily sold through the municipal markets and road-side vendor stalls $[8,14]$. In the few retail shops and supermarkets where fresh fruits and vegetables are sold, trade was restricted to small quantities and a limited range of primarily imported horticultural products (such as temperate fruits and potato), or the re-selling of product sourced from the municipal market [8]. This study did not seek to quantify consumer accessibility to fresh fruits and vegetables or the price or volume of horticultural product traded through Tonga's domestic markets.

On Tongatapu Island, market surveys were undertaken at the Talamahu municipal market in Nuku'alofa, the Siamelie road-side cluster market in Ma'ufanga (Ma'ufanga village is only $2.1 \mathrm{~km}$ from Nuku'alofa), and the road-side vendor stalls located throughout the island.

On 'Utu Vava'u Island, market surveys were limited to the Utukalongalu municipal market, in the main town of Neiafu. An initial plan to include road-side vendors on 'Utu Vava'u Island was discontinued early in the study due to an insufficient number of vendors present.

\subsection{Survey Design and Ethics Approval}

Fruit and vegetable vendor surveys were undertaken throughout 2019 to account for possible seasonality differences. On Tongatapu Island, surveys were conducted in February to March, May to June, September, and November to December. A total of 238 vendors were surveyed on Tongatapu Island, consisting of 86 vendors at the Talamahu municipal market, 41 vendors at the Siamelie road-side cluster market, and 111 road-side vendors. Variable sampling between markets was due to differences in the number of vendors present within each market cohort.

On 'Utu Vava'u Island, vendor surveys were limited to Utukalongalu municipal market, and undertaken in February, June and September. In total, 54 municipal market vendors were surveyed. The Utukalongalu municipal market was a comparatively small regional market, with approximately 
15 to 30 vendors and vendor market attendance temporally concentrated to the key trading days of Friday and Saturday.

The market surveys involved a short semi-structured interview undertaken in the local language, with each interview lasting 5 to $10 \mathrm{~min}$. The survey included 27 questions covering vendor stall location, farm location (village or farm location where product was sourced), crop type, harvesting practice, packaging, transport logistics, potential vendor strategies to reduce loss, and crops or villages anticipated to incur elevated postharvest loss. Survey data was recorded using tablets with GIS location capacity incorporating KokoToolBox software ${ }^{\mathrm{TM}}$ (Harvard Humanitarian Initiative, Cambridge, MA, USA), with vendor responses recorded in English. To reduce error and ensure a standard approach when interviewing participants, all enumerators received prior training as well as refresher training. All interviews were completed in full compliance with approval from the University of the Sunshine Coast, Australia, Human Research Ethics Committee (A16814).

\subsection{Postharvest Loss}

Postharvest loss was determined based on vendor recall, consistent with other Pacific market studies [16-18]. Loss was calculated on the basis of weight, volume or amount of product removed for commercial sale by the vendor, proportional to the total consignment sourced by the vendor. Calculated postharvest loss does not account for potential re-use (i.e., unsold product being re-directed for home use or animal feed) or on-farm loss (i.e., pre-transport grading). Postharvest loss presented in this paper represents the level of loss incurred on the day of survey. Given some product was traded over several days, the level of postharvest loss per consignment is a multiple of the market storage duration and percent of daily loss. Given horticultural value chains in Tonga rarely involve middle actors (between farmers and market vendors) [16-18], and that there was limited on-farm grading observed during pre-trial farm visits, postharvest loss was only quantified at the market end of the chain.

\subsection{Data Analysis}

Significant differences in mean time of transport from farm to market, between harvesting and product arrival at market and the mean time since product was harvested, were tested using analysis of variance (ANOVA) followed by Tukey's multiple comparison test at $p<0.05$. Significant differences in horticultural loss among vendors from different market were analyzed by the Kruskal-Wallis $\mathrm{H}$ test (IBM SPSS Statistics version 24).

\section{Results}

The location of the fruit and vegetable markets and road-side vendor stalls on Tongatapu Island are shown in Figure 2A. Road-side vendor stalls were concentrated along the main access roads into the capital of Nuku'alofa, with the Talamahu municipal market and the Siamelie road-side cluster market located in the central business districts of Nuku'alofa and Ma'ufanga, respectively. There were very few road-side vendors and no municipal markets present on the southern or northeastern parts of Tongatapu. A heat map of vendor trading, based on number of road-side market vendors per location, is shown in Figure 2B. The greatest concentration of road-side vendors was in the urban-based villages of Ma'ufanga, Kolofo'ou, Kolomotu'a, and Havelu (i.e., a village is a geographic division within the Tongan census), all of which were within a $4 \mathrm{~km}$ radius of the central business district of Nuku'alofa (Figure 2B). These villages were charaterised as having a relatively high population density and a large number $(>58 \%)$ of households not producing crops for sale or home use (Figure $2 \mathrm{C}$ ). Most of these households are likely to be reliant on the commercial food system or communal sharing to source their fruits and vegetables. Elevated road-side vendor participation in the township of Mu'a in eastern Tongatapu, between the villages of Lapaha and Takakamotonga (Figure 2B), is interesting given its relatively small population, rural location and moderate number of households not producing crops for sale or home use. 


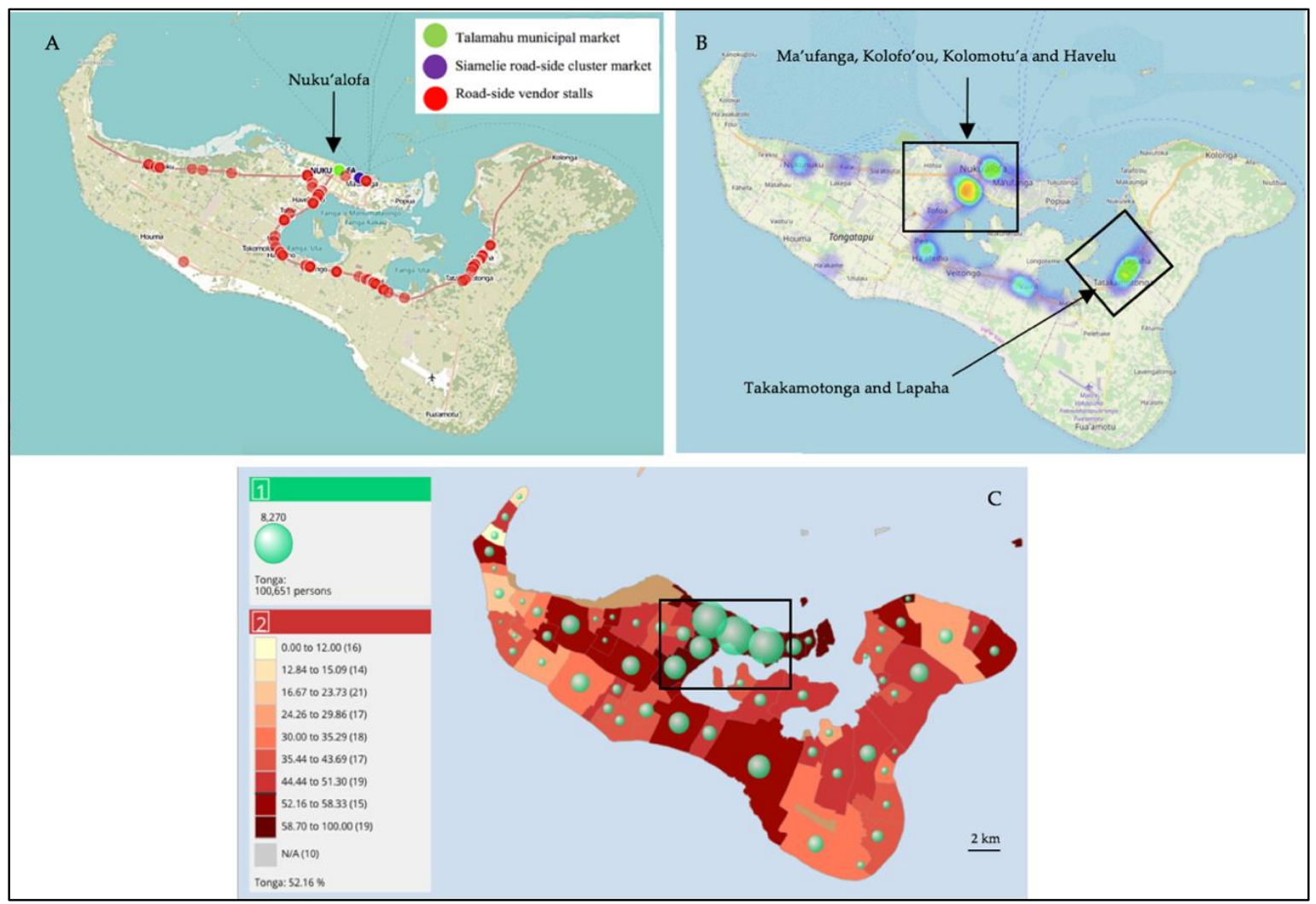

Figure 2. (A) The location of commercial fresh fruit and vegetable vendors on Tongatapu Island, Tonga. (B) Heat map of road-side markets on Tongatapu Island (colour intensity is proportional to the number of vendor stalls in a given location). (C) Households on Tongatapu Island not producing crops for sale or home use, with population density overlay. Map source: (A,B) Openstreet map and KoBoToolBox ${ }^{\mathrm{TM}}$ with survey data overlays. (C) PopGIS Tonga 2016 Population and housing census data. Tonga Department of Statistics.

The road-side vendors throughout Tongatapu Island were observed to frequently co-locate with other commercial enterprises (i.e., petrol stations and retail outlets), or were positioned adjacent to key public amenities (i.e., hospitals and schools), possibly enhancing their level of consumer accessibility. The presence of several public amenities in $\mathrm{Mu}^{\prime}$ a township might explain the concentration of vendors in Lapaha and Takakamotonga. Using Google Earth Pro ${ }^{\mathrm{TM}}$ to calculate linear distance and the GIS location of vendors, most households on Tongatapu Island were located within $10 \mathrm{~km}$ of a commercial outlet selling fresh fruit or vegetables, with road-side vendors the most accessible with respect to travel distance.

On the northern Island of 'Utu Vava'u, commercially sourced fresh horticultural product was restricted to the Utukalongalu municipal market, located in the main urban population centre of Neiafu (Figure 3A,B). While road-side vendors were present, vendor participation was very limited and typically involved single-day trading. Using Google Earth Pro ${ }^{\mathrm{TM}}$ to calculated non-linear path distance using on the existing road network, most households on Utu Vava'u Island were located within $15 \mathrm{~km}$ of the Utukalongalu municipal market.

The location of farms supplying the Talamahu municipal market and the Siamelie road-side cluster market on Tongatapu Island are shown in Figure 4. Whilst the Talamahu and Siamelie markets are in close proximity to each other, the network of farms supporting these markets was slightly different. Vendors at the Talamahu municipal market sourced from farms in Vaini and Nukunuku districts and, to a lesser extent, Kolofo'ou district (western Tongatapu) and Tatakamotonga district (eastern Tongatapu) (Figure 4A, Table 1). There was also limited supply from 'Eua Island (Table 1). In comparison, the Siamelie road-side cluster market primarily sourced from farms in the 
Tatakamotonga, Nukunuku and the western portion of Vaini district (Figure 4B). The main point of difference between these two markets was a greater prevalence of supply from the Tatakamotonga district into the Siamelie market, and a greater supply from Vaini district into the Talamahu municipal market. The reason for this disparity is not clear. Although the Siamelie road-side cluster market was located next to the inter-island passenger ferry terminal, no inter-island-sourced product was mentioned in the vendor survey responses. The location of farms supplying road-side vendors on Tongatapu Island could not be determined, as road-side vendors were unwilling to identify. Farms supplying the Utukalongalu municipal market, Utu Vava'u Island, are shown in Figure 5. Utukalongalu vendors primarily sourced produce from one of five villages-Leimatu'a, Mataika, Tefisi, Ta'anea and Panagaimotu (Figure 5). Of the 43 villages on Vava'u [12], 54.6\% of the product supplying the Utukalongalu market was sourced from farms associated with just three villages_Leimatu'a, Mataika and Tefisi (Table 1).

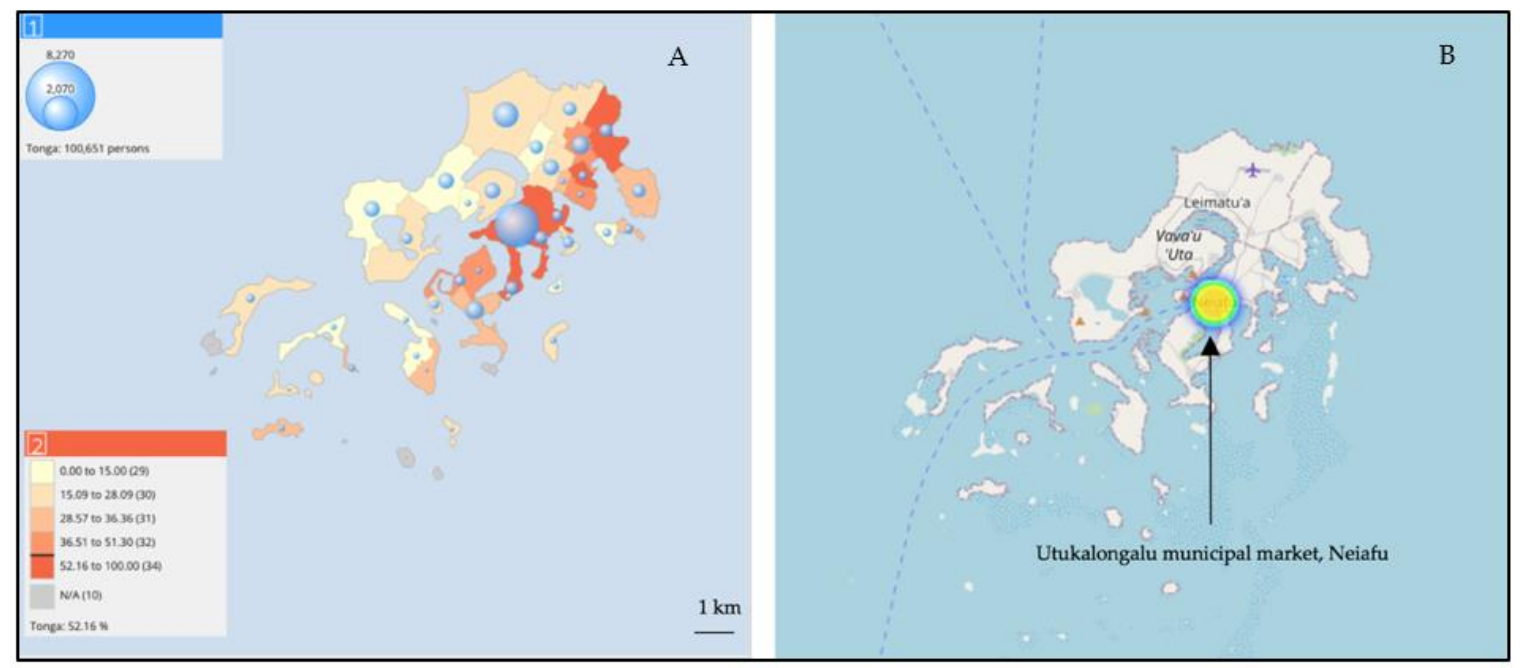

Figure 3. (A) Number of households on 'Utu Vava'u Island not producing crops for sale or home use, with population density overlay. (B) Heat map of 'Utu Vava'u Island, illustrating the concentration of market vendors at the Utukalongalu municipal market. Map source: (A) PopGIS Tonga 2016 Population and housing census data. Tonga Department of Statistics. (B) Openstreet map and KoBoToolBox ${ }^{\mathrm{TM}}$ with survey data overlays.

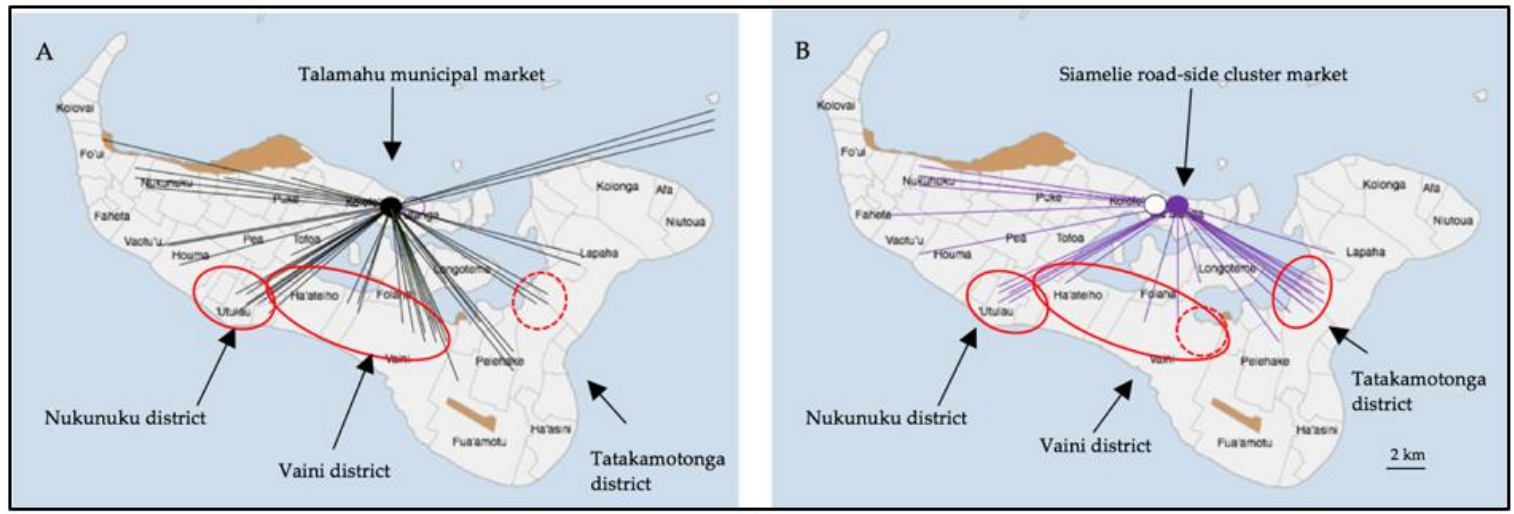

Figure 4. The location of farms supplying the main fruit and vegetable markets on Tongatapu Island. (A) Talamahu municipal market in central Nuku'alofa, Tongatapu Island. (B) Siamelie road-side cluster market Ma'ufanga, Tongatapu Island. Map source: Open street map 2019 and KoBoToolBox ${ }^{\mathrm{TM}}$ with survey overlays. 
Table 1. The horticultural production centres supplying Tonga's fruit fresh and vegetable markets, associated transport logistics, and market vendor throughput.

\begin{tabular}{|c|c|c|c|c|}
\hline \multirow[b]{2}{*}{ Market Vendor Practice } & \multicolumn{2}{|c|}{ 'Utu Vava'u Island } & \multicolumn{2}{|c|}{ Tongatapu Island } \\
\hline & $\begin{array}{l}\text { Utukalongalu } \\
\text { Municipal } \\
\text { Market* }\end{array}$ & $\begin{array}{l}\text { Talamahu } \\
\text { Municipal } \\
\text { Market } * *\end{array}$ & $\begin{array}{l}\text { Siamelie } \\
\text { Road-Side Cluster } \\
\text { Market }\end{array}$ & $\begin{array}{l}\text { Road-Side } \\
\text { STALLS **** }\end{array}$ \\
\hline \multicolumn{5}{|l|}{ Product origin } \\
\hline Intra-island-located farms (\%) & 100 & 93 & 100 & 95.5 \\
\hline Inter-island-located farms (\%) & 0 & 7 & 0 & 4.5 \\
\hline \multicolumn{5}{|l|}{$\begin{array}{l}\text { Main production sites (\% vendors } \\
\text { sourcing from defined villages } \\
\text { and districts) }\end{array}$} \\
\hline \multicolumn{5}{|l|}{ 'Utu Vava'u Island } \\
\hline Leimatu'a district & 49.6 & - & - & - \\
\hline Leimatu'a village & 34.0 & - & - & - \\
\hline Mataika village & 11.2 & - & - & - \\
\hline Hihifo district & 15.1 & - & - & - \\
\hline Tefisi village & 9.4 & - & - & - \\
\hline Neiafu district & 11.3 & - & - & - \\
\hline \multicolumn{5}{|l|}{ Tongatapu Island } \\
\hline Tatakamotonga district & - & 7.7 & 24.4 & $\mathrm{n} / \mathrm{a}$ \\
\hline Nukunuku district & - & 17.8 & 19.5 & $\mathrm{n} / \mathrm{a}$ \\
\hline Vaini district & - & 22.2 & 12.2 & $\mathrm{n} / \mathrm{a}$ \\
\hline Kolovai district & - & 3.3 & 12.2 & $\mathrm{n} / \mathrm{a}$ \\
\hline \multicolumn{5}{|l|}{$\begin{array}{l}\text { Mode of product transport from } \\
\text { farm to market (\% of vendors) }\end{array}$} \\
\hline Private car & 21.6 & 25.6 & 29.3 & 27.9 \\
\hline Minivan or local bus & 58.8 & 11.6 & 9.8 & 2.7 \\
\hline Truck & 17.6 & 52.3 & 61.0 & 61.3 \\
\hline Taxi & 0 & 1.2 & 0 & 0 \\
\hline Boat or ferry & 2.0 & 7.0 & 0 & 4.5 \\
\hline Walk & 0 & 0 & 0 & 2.7 \\
\hline \multicolumn{5}{|l|}{$\begin{array}{l}\text { Packaging type used } \\
\text { ( } \% \text { of vendors })\end{array}$} \\
\hline Nil packaging & 20.3 & 44.8 & 47.6 & 50.0 \\
\hline Tray & 1.6 & 5.2 & 4.8 & 2.6 \\
\hline Plastic bucket & 20.3 & 17.7 & 14.3 & 12.3 \\
\hline Plastic crate & 18.8 & 16.7 & 14.3 & 7.9 \\
\hline Traditional woven basket & 26.6 & 7.3 & 7.1 & 12.3 \\
\hline Small bag (approx. 10 kg) & 10.9 & 6.3 & 9.5 & 9.7 \\
\hline Medium bag (approx. 11 to $20 \mathrm{~kg}$ ) & 1.6 & 2.1 & 0 & 3.5 \\
\hline Large bag (>21 kg) & 0 & 0 & 0 & 1.8 \\
\hline
\end{tabular}


Table 1. Cont.

\begin{tabular}{|c|c|c|c|c|}
\hline \multirow[b]{2}{*}{ Market Vendor Practice } & \multicolumn{2}{|c|}{ ‘Utu Vava'u Island } & \multicolumn{2}{|c|}{ Tongatapu Island } \\
\hline & $\begin{array}{l}\text { Utukalongalu } \\
\text { Municipal } \\
\text { Market* }\end{array}$ & $\begin{array}{l}\text { Talamahu } \\
\text { Municipal } \\
\text { Market }\end{array}$ & $\begin{array}{l}\text { Siamelie } \\
\text { Road-Side Cluster } \\
\text { Market }\end{array}$ & $\begin{array}{l}\text { Road-Side } \\
\text { STALLS **** }\end{array}$ \\
\hline $\begin{array}{l}\text { Mean time to transport product } \\
\text { from farm to market (mins) }\end{array}$ & $20.0 a$ & $\begin{array}{l}114.7 b c \\
(48.5 a)\end{array}$ & $57.0 a b$ & $\begin{array}{c}39.8 a \\
(35.4 a)\end{array}$ \\
\hline $\begin{array}{l}\text { Mean time between harvesting } \\
\text { and product arrival at market (h) \# }\end{array}$ & $16.4 a b$ & $13.1 b$ & $15.3 b$ & $24.8 a$ \\
\hline \multicolumn{5}{|l|}{$\begin{array}{l}\text { Mean time since product was } \\
\text { harvested (including market } \\
\text { storage) }(\mathrm{h})^{\mathrm{V}}\end{array}$} \\
\hline Fruits & $28.0 a$ & $33.6 b$ & $35.7 a$ & $46.3 c$ \\
\hline Vegetables & $9.6 a$ & $8.9 a$ & $25.3 a$ & $23.6 a$ \\
\hline Root crops & $25.7 a$ & $34.4 b c$ & $23.9 a$ & $37.7 a b$ \\
\hline All crops ${ }^{\wedge}$ & $23.9 a$ & $28.2 a$ & $29.5 a$ & $38.9 a$ \\
\hline
\end{tabular}

Data presented is based on sampling throughout 2019 to account for possible seasonality effects. ${ }^{*} \mathrm{~N}=54$ vendors surveyed. ${ }^{* *} \mathrm{~N}=86$ vendors surveyed. ${ }^{* * *} \mathrm{~N}=41$ vendors surveyed. ${ }^{* * * *} \mathrm{~N}=111$ vendors surveyed. $\mathrm{n} / \mathrm{a}$. Data not available. \# Mean time between harvesting and product arrival was calculated based on vendor response but excludes crops harvested $>2$ days ago to avoid inclusion of possible in-market storage. ${ }^{V}$ Values followed by different letters on the same column are significantly different (ANOVA, $p<0.05$ ). ^ Values followed by different letters on the same segment are significantly different (ANOVA, $p<0.05$ ). Values in parenthesis exclude inter-island value chains.

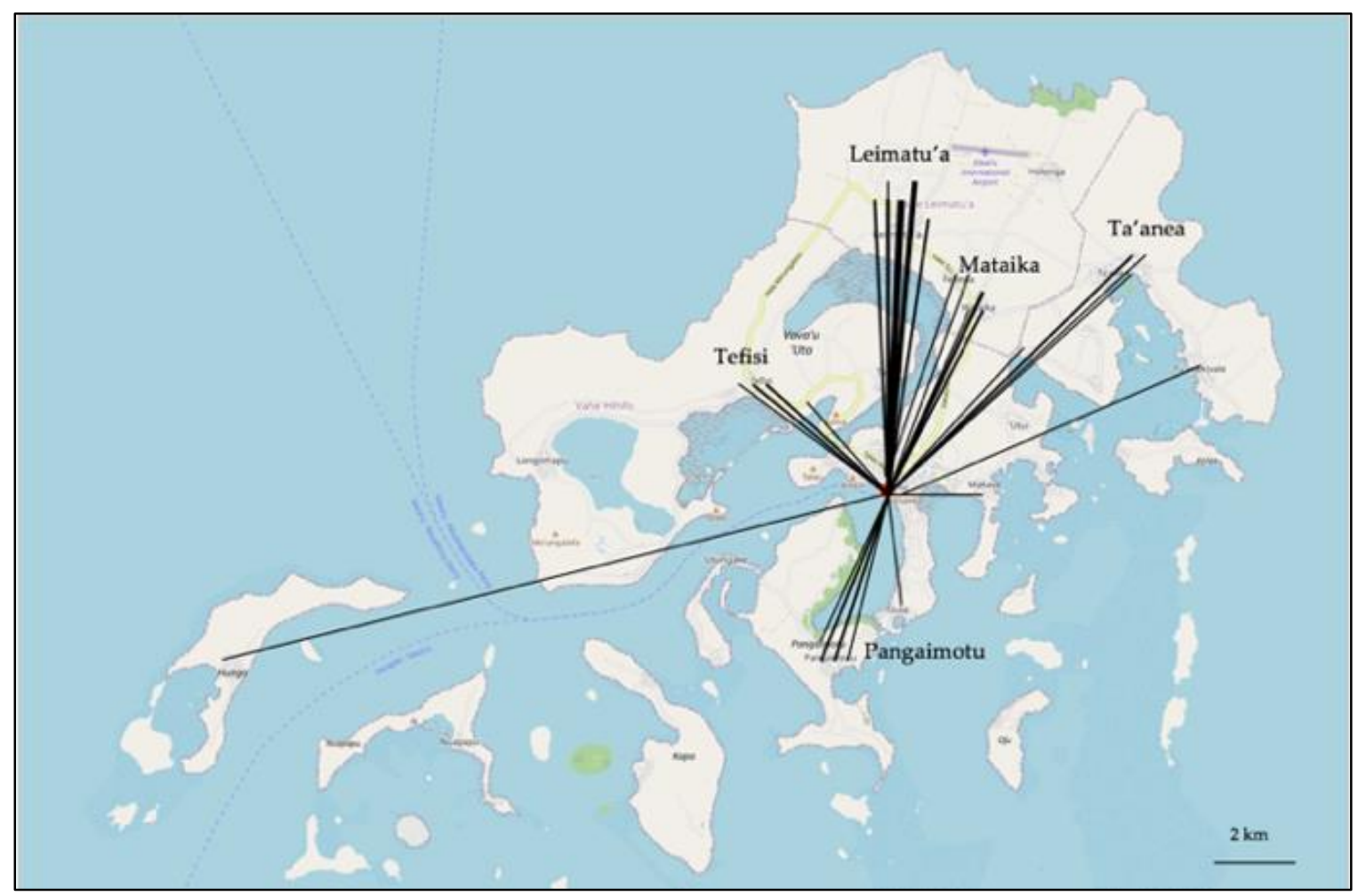

Figure 5. The location of farms supplying fruits and vegetables into the Utukalongalu municipal market, Neiafu, Utu Vava'u Island. Map source: Open street map 2019 and KoBoToolBox ${ }^{\mathrm{TM}}$ with survey result overlays.

Intra-island horticultural transport logistics into the Talamahu municipal market, the Siamelie road-side cluster market or the road-side market was predominantly by truck (Table 1). Less commercial modes of product transport (private car, minivan, taxi and walking) collectively accounted for 
approximately $40 \%$ of the market supply, possibly reflecting the proportion of semi-subsistence farmers supplying these markets. In contrast, intra-island transport logistics into Utukalongalu municipal market, Utu Vava'u Island was primarily by minivan, consistent with the reduced volume of product supplying this market, shorter transport distance and possibly reduced access to commercial transport options (Table 1).

With most intra-island farms on Tongatapu Island located less than $25 \mathrm{~km}$ from the municipal market, product transport time was very short ( 35 to $57 \mathrm{~min}$ ) (Table 1). In spite of the obvious benefits of their close proximity to the market, there was often a delay of up to $25 \mathrm{~h}$ between harvest and transport, with product commonly stored overnight prior to transport to the market the following day (Table 1). A similar transport lag occurred in chains supplying the Utukalongalu municipal market. This delay may be due to challenges in accessing labour or commercial transport, or might simply reflect on-farm practices such as sorting, washing, grading, or packing undertaken prior to transport. A further possible explanation for this delay might involve the time required to consolidate multi-product consignments for co-transport (i.e., a common practice).

At the time of individual vendor surveys, most product presented for sale had been harvested 24 to $39 \mathrm{~h}$ prior (Table 1). This period represents delayed market transport and some market storage. With $39 \%$ to $50 \%$ of product traded through markets in Tongatapu sold on the day of arrival (Table 2), the time between harvesting and consumer purchase for most crops is anticipated to be up to $48 \mathrm{~h}$. Vegetable supply chains into the Talamahu municipal market and road-side vendors were significantly quicker. There was little difference between vegetable, root crop or fruit chains into the Siamelie and Utukalongalu markets (Table 1 ). When prolonged market storage ( $>2$ days) was reported by vendors, it was usually associated with watermelon, tomato, taro, sweet potato, and banana.

Table 2. Frequency of vendor market participation and relative rate of product trading in fruit and vegetable markets on 'Utu Vava'u and Tongatapu Islands, Tonga.

\begin{tabular}{|c|c|c|c|c|}
\hline & \multirow{2}{*}{$\begin{array}{c}\begin{array}{c}\text { Utu Vava'u } \\
\text { Island }\end{array} \\
\begin{array}{c}\text { Utukalongalu } \\
\text { Municipal } \\
\text { Market * }\end{array}\end{array}$} & \multicolumn{3}{|c|}{ Tongatapu Island } \\
\hline & & $\begin{array}{l}\text { Talamahu } \\
\text { Municipal } \\
\text { Market } \\
* *\end{array}$ & $\begin{array}{l}\text { Siamelie } \\
\text { Road-Side Cluster } \\
\text { Market } \\
* * *\end{array}$ & $\begin{array}{l}\text { Road-Side } \\
\text { Stalls **** }\end{array}$ \\
\hline \multicolumn{5}{|l|}{$\begin{array}{l}\text { Frequency of vendor } \\
\text { participation at the market }(\%)\end{array}$} \\
\hline Daily (6 days a week) & 39.6 & 58.1 & 70.7 & 73.9 \\
\hline Often ( 3 to 4 times a week) & 18.9 & 20.9 & 22.0 & 10.8 \\
\hline 1 to 2 times a week & 22.6 & 15.1 & 7.3 & 4.5 \\
\hline Once a week & 18.9 & 3.5 & 0 & 10.8 \\
\hline \multicolumn{5}{|l|}{$\begin{array}{l}\text { Percent of vendors selling } \\
\text { product within the } \\
\text { defined period }\end{array}$} \\
\hline Product will be sold within $4 \mathrm{~h}$ & 13.0 & 4.7 & 2.4 & 6.3 \\
\hline Product will be sold within $6 \mathrm{~h}$ & 9.3 & 14.0 & 9.8 & 6.3 \\
\hline Product will be sold within $8 \mathrm{~h}$ & $46.3(68.6)$ & $23.3(42.0)$ & $26.8(39.0)$ & $37.8(50.4)$ \\
\hline Product likely sold within $48 \mathrm{~h}$ & 24.1 & 9.3 & 12.2 & 2.7 \\
\hline Product will take $>2$ days to sell & 7.4 & 20.9 & 24.4 & 36.0 \\
\hline $\begin{array}{l}\text { Vendor not sure when product } \\
\text { will be sold }\end{array}$ & 0 & 25.6 & 26.8 & 9.9 \\
\hline \multicolumn{5}{|c|}{$\begin{array}{l}\text { Data presented is based on sampling throughout } 2019 \text { to account for possible seasonal variability. }{ }^{*} \mathrm{~N}=54 \text { vendors } \\
\text { surveyed. }{ }^{* *} \mathrm{~N}=86 \text { vendors surveyed. }{ }^{* * *} \mathrm{~N}=41 \text { vendors surveyed. }{ }^{* * *} \mathrm{~N}=111 \text { vendors surveyed. Values in } \\
\text { parenthesis represent the percent of vendors who will sell all product within the same trading day. }\end{array}$} \\
\hline \multicolumn{5}{|c|}{$\begin{array}{l}\text { Horticultural packaging in Tonga was consistent with the typical wide range of options seen } \\
\text { outh Pacific smallholder farmer value chains }[17,18] \text { (Table } 1 \text { ). A significant proportion of } \\
\text { duct ( } 45 \% \text { to } 50 \% \text { ) supplying the markets in Tongatapu was transported loose (i.e., nil packaging). }\end{array}$} \\
\hline
\end{tabular}


This practice principally involved heavy produce such as giant swamp taro, watermelon, taro, yam and squash. Plastic re-usable crates were used in $12 \%$ to $20 \%$ of value chains. This represents a relatively high adoption rate for this type of packaging, relative to smallholder value chains elsewhere in the South Pacific $[17,18]$. Utukalongalu municipal market had the highest percent for adoption of plastic crates and lowest use of nil packaging, compared to all other markets in Tonga (Table 1).

The frequency of vendor participation at the various markets provides some insight into the operation of these markets (Table 2). Most road-side vendors traded six days a week. In comparison, vendor participation in Talamahu and Utukalongalu municipal markets was slightly less frequent, especially in the Utukalongalu municipal market. This is likely to imply a larger proportion of casual vendors within the municipal markets resulting in a level of concentrated trading (commonly Friday and Saturday). Further, road-side vendors may be more actively sourcing product from multiple farms or municipal market sources, creating a greater continuity of product supply. Vendor interviews also highlighted the practice whereby vendors at the Talamahu provided temporary caretaker custodianship to adjacent vendor stalls, lessening the need for regular market attendance. This was made possible by vendors from the same community or village often being located within clusters within the municipal market. It is possible that road-side vendors had less access to labour-sharing opportunities, necessitating prolonged market attendance. One road-side vendor trading watermelon indicated that it could take up to 2 weeks of continuous vendor trading to sell a consignment.

Postharvest loss in Tonga's fruit and vegetable markets was very low, at $1.4 \%$ to $5.3 \%$ (Table 3 ). Most vendors did not report any loss, with postharvest loss limited to approximately $9 \%$ of all vendors, increasing to $25 \%$ in the road-side vendors on Tongatapu. For those vendors that did incur postharvest loss, mean loss was between $19 \%$ and $27 \%$.

Table 3. Mean postharvest horticultural loss and the proportion of vendors reporting postharvest loss in the fruit and vegetable markets on 'Utu Vava'u and Tongatapu Islands, Tonga.

\begin{tabular}{|c|c|c|c|c|}
\hline & \multicolumn{2}{|c|}{ Tongatapu Island } & \multicolumn{2}{|c|}{ ‘Utu Vava'u Island } \\
\hline & $\begin{array}{l}\text { Utukalongalu } \\
\text { Municipal } \\
\text { Market * }\end{array}$ & $\begin{array}{l}\text { Talamahu } \\
\text { Municipal } \\
\text { Market ** }\end{array}$ & $\begin{array}{c}\text { Siamelie } \\
\text { Road-Side Cluster } \\
\text { Market }\end{array}$ & $\begin{array}{l}\text { Road-Side } \\
\text { Stalls } * * * *\end{array}$ \\
\hline $\begin{array}{l}\text { Mean daily postharvest } \\
\text { loss-all vendors }(\%) \#\end{array}$ & $2.1 a$ & $2.2 a$ & $1.4 a$ & $5.3 a$ \\
\hline \multicolumn{5}{|l|}{$\begin{array}{l}\text { Percent of vendors reporting } \\
\text { postharvest loss }\end{array}$} \\
\hline Yes & 9.3 & 9.3 & 9.8 & 25.2 \\
\hline No & 90.7 & 90.7 & 90.2 & 74.8 \\
\hline $\begin{array}{l}\text { Mean postharvest loss (\%) } \\
\text { (only vendors reporting loss) }\end{array}$ & $22.7 a$ & $26.9 a$ & $19.1^{\wedge}$ & $21.2 a$ \\
\hline \multicolumn{5}{|c|}{$\begin{array}{l}\text { Data presented is based on sampling throughout } 2019 \text { to account for possible seasonal variability. }{ }^{*} \mathrm{~N}=54 \\
\text { vendors surveyed. }{ }^{* *} \mathrm{~N}=86 \text { vendors surveyed. }{ }^{* * *} \mathrm{~N}=41 \text { vendors surveyed. }{ }^{* * * *} \mathrm{~N}=111 \text { vendors surveyed. } \\
\text { \# Postharvest loss does not account for potential re-use due to product being re-directed for home use or animal } \\
\text { feed, or on-farm loss associated with pre-harvest pest, diseases or pre-transport grading. Insufficient number of } \\
\text { vendors reporting loss for statistical analysis. Values followed by different letters on the same row are significantly } \\
\text { different (Kruskal-Wallis H test, } p<0.05 \text { ). }\end{array}$} \\
\hline
\end{tabular}

The spatial distribution of market vendors on Tongatapu Island reporting postharvest loss is shown in Figure 6. Vendors with postharvest loss were evenly distributed along the roads into Nuku'alofa, often adjacent to vendors with no loss. There was no discernable clustering of adversely impacted road-side vendors, implying that the location of the vendor stall was unlikely to be a postharvest risk factor. 


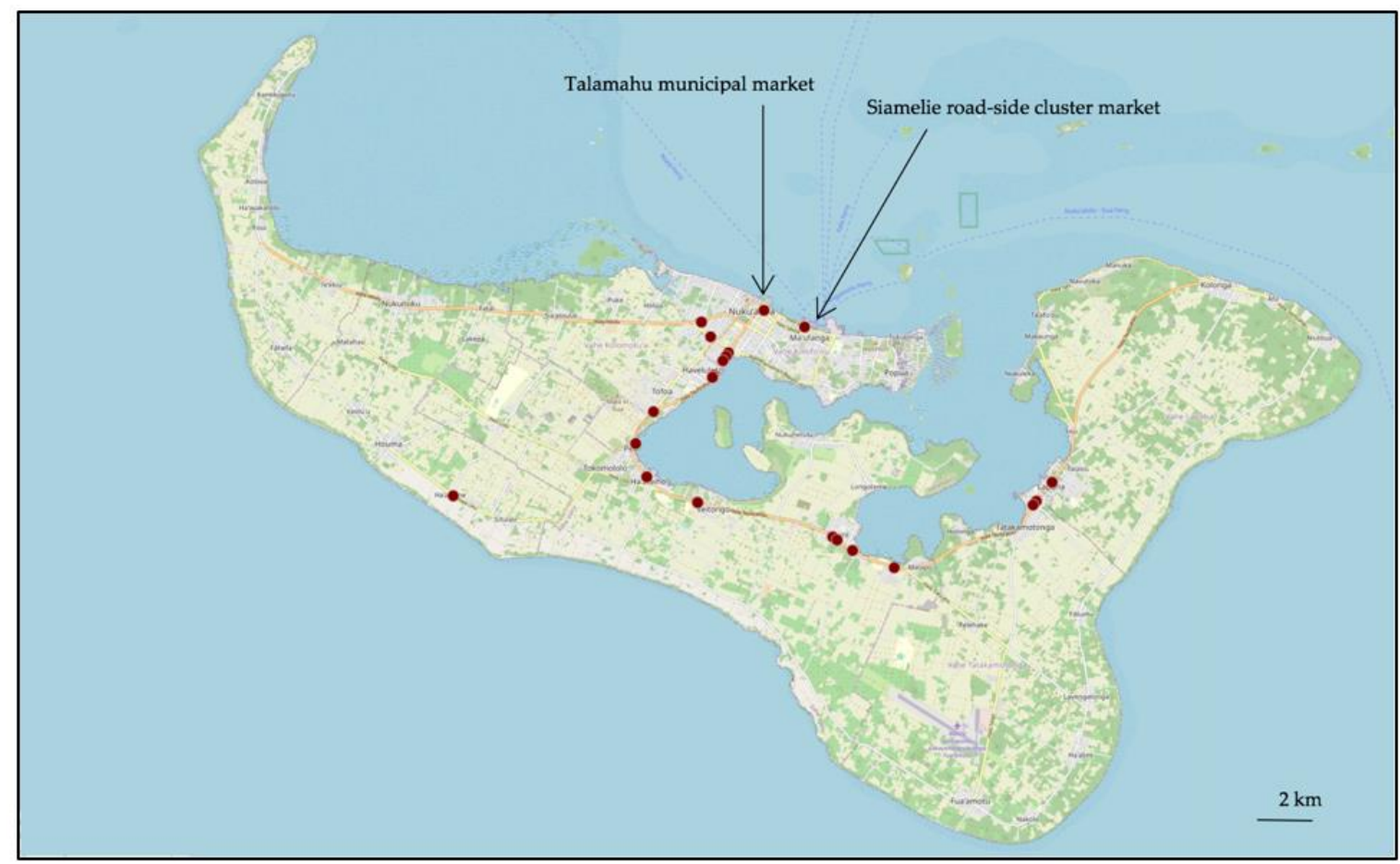

Figure 6. The spatial distribution of market vendors on Tongatapu Island who reported postharvest loss. Map source: Open street map 2019 and KoBoToolBox ${ }^{\mathrm{TM}}$ with survey result overlays.

There was little difference between fruit, vegetable and root crop value chains in terms of their vulnerability to postharvest loss (Table 4). However, tomato, taro, watermelon, banana and plantain were perceived by vendors to have an elevated risk of incurring postharvest loss. Potentially high-perishable crops, such as leafy vegetable, were infrequently associated with loss, possibly reflecting the low intensity of trading of leafy vegetables within Tonga's horticulture food system.

Postharvest loss was due to pest, diseases, physical damage, stage of ripeness and, to a lesser extent, product size, consistent with pre-harvest, transport and market storage risk factors (Table 4).

Vendors reported that the incidence of postharvest loss increased following rain or during the summer months (Table 4). While it is logical to assume elevated postharvest loss during the warmer summer months, the incidence of postharvest loss associated with vendor surveys undertaken during summer (i.e., November to December) period did not support this conclusion.

Vendors used a range of strategies in an attempt to reduce the incidence or severity of postharvest loss. Most vendors sought to limit the volume of product being sourced from farms to match anticipated daily consumer demand (Table 4). Vendors also actively used price discounting and competitive pricing, whereby vendors were prepared to incur a partial economic loss presumably to avoid prolonged product storage and associated loss. More direct postharvest interventions included on-farm grading, covering the product overnight and, to a lesser extent, packing and the application of water were reported (Table 4). The infrequent use of simple low-cost strategies such as shade, might indicate limited postharvest handling practice awareness amongst vendors.

The potential effectiveness of postharvest loss-mitigation strategies can be explored if the cohort of vendors incurring loss and their mitigations strategies are separately considered (Table 4). Vendors reporting postharvest loss were less likely to regulate farm supply (37\%) or cover product overnight (28\%), but more likely to use price discounting at the end of the day (54\%). Although this infers that market-regulated supply was an effective postharvest loss-mitigation strategy, this disparity may simply reflect the type of crops being traded by vendors incurring postharvest loss. Crops likely to incur elevated loss are more likely to necessitate prolonged market storage due to in-market ripening 
(i.e., tomato and banana) or possible slow market throughput (i.e., taro and watermelon), and, as a result, there was less vendor capacity or need to regulate supply.

Table 4. Crop type, product quality defects, and external factors attributed to postharvest loss, based on percent of market vendor response.

\begin{tabular}{|c|c|}
\hline Vendor Perception & $\begin{array}{c}\text { Percent Market Vendors } \\
\text { (All Markets and Locations) * }\end{array}$ \\
\hline \multicolumn{2}{|l|}{ Crop type most likely to incur loss } \\
\hline Fruits ** & 31.7 \\
\hline Vegetable & 35.6 \\
\hline Root crops & 32.7 \\
\hline \multicolumn{2}{|l|}{ Market storage } \\
\hline Product stored in market for $>2$ days & $25.7(38.9)^{* * *}$ \\
\hline \multicolumn{2}{|l|}{ Horticultural product most likely to incur loss $* * *$} \\
\hline Tomato & 15.1 \\
\hline Taro (multiple types) & 8.6 \\
\hline Banana and Plantain & 7.2 \\
\hline Watermelon & 6.5 \\
\hline Taro leaf & 3.4 \\
\hline \multicolumn{2}{|l|}{ Product quality (physical) defects attributed to loss } \\
\hline Postharvest rots & 92.7 \\
\hline Product over-ripe & 78.0 \\
\hline Pest damage & 75.6 \\
\hline Bruising or physical damage & 75.6 \\
\hline Product size & 22.0 \\
\hline \multicolumn{2}{|l|}{ External contributors likely to elevate vendor loss } \\
\hline Harvesting after rain & 48.3 \\
\hline Trading during summer & 44.9 \\
\hline Trading after cyclones or high wind events & 4.3 \\
\hline Late season harvesting & 1.1 \\
\hline
\end{tabular}

Vendor strategies to reduce product loss

Limited quantity of product sourced from farms to match consumer demand

$67.1(37.0)^{* * *}$

\begin{tabular}{cc}
\hline Price discounting at the end of the day & $47.9(54.0)$ \\
\hline Cover product (if stored over-night) & $36.0(28.0)$ \\
\hline Grade product on-farm & $35.3(28.5)$ \\
\hline Store product in plastic bag prior to sale & $10.6(11.4)$ \\
\hline Sell at a lower price to other vendors & $8.6(5.7)$ \\
\hline Spray water on product while being displayed & $2.3(0)$ \\
\hline Ensure vendor stall has adequate shade & $1.0(0)$ \\
\hline
\end{tabular}

Data presented is based on sampling throughout 2019 to account for possible seasonality effects. ${ }^{*} \mathrm{~N}=292 .{ }^{* *}$ Crop type is based on botanical definitions. ${ }^{* * *}$ Values in parenthesis represent only vendors incurring postharvest loss. 


\section{Discussion}

Fresh fruits and vegetables in Tongatapu Island were commercially traded through a centrally located municipal market and a network of road-side vendors. These markets were concentrated in urban centres that had a large portion of households potentially reliant on commercially sourced fresh food. On Utu Vava'u Island, commercial trade of fresh fruit and vegetables was more spatially restricted, with product sourced from the Utukalongalu municipal market supported by a small network of farms. While this horticultural market and distribution system is consistent with other small-island developing states across the South Pacific Island, there are some differences. In Fiji, the horticultural distribution system is dominated by a large network of municipal markets, numerous road-side cluster markets, and, to a lesser extent, single road-side vendor stalls [16]. The presence of up to thirteen municipal markets throughout Fiji [19], several in small rural population centres, is in direct contrast to the single central municipal market on Tongatapu and Utu Vava'u Islands. In the Solomon Islands, road-side vendors are more likely to be incorporated into relatively large cluster markets concentrated in peri-urban communities within the greater Honiara district $[18,20,21]$. In Samoa, the horticultural market system is in an apparent rapid transition, with the progressive closure of regional markets and the emergence of numerous supermarkets, road-side cluster markets, and food and lifestyle night markets [18,22]. Differences in the horticultural market and distribution system across the region are likely to reflect local socio-economic and population demographics, infrastructure and transport networks, the spatial distribution of horticultural production, and consumer purchasing behaviour. However, with few published studies of South Pacific horticultural markets to draw on, the underlying drivers shaping horticultural markets in the region remains somewhat subjective.

Product supplying the fruit and vegetable markets on Tongatapu and Utu Vava'u Islands was primarily sourced from close proximity intra-island farms, with few inter-island value chains evident. Small spatial differences in the distribution of farms supporting the Talamahu or Siamelie market reflected a variance in the intensity of supply rather than differential source locations. Farms in Lapaha and Tatakamotonga are more likely to supply the Siamelie road-side cluster market, whereas farms in Vaini tended to supply the Talamahu municipal market. Although the farm supply network into the Utukalongalu municipal market on Utu Vava'u Island was similarly spatially diverse, much of the overall volume of trade was linked to three villages, highlighting a possible underlying food security vulnerability. It is unclear whether this semi-concentrated market supply simply reflects a distribution of commercially active farms on Utu Vava'u Island, or vendor demographics and selectively sourcing from their own farm or farms within their local community.

Road-side vendors on Tongatapu Island were reticent to disclose their farm supply networks. Ika [8] similarly mentions a lack of information regarding road-side vendor supply. Based on road-side vendor practice in other Pacific fruit and vegetable markets [18,21,23], a significant portion of road-side vendor trade in Tonga is likely to be sourced from the municipal market. Hau'ofa [14], in an older study of Tongan fruit and vegetable markets, indicated that vendors rarely self-identified as middle men or traders due to perceived lower social status. Georgeou et al. [23] reported a similar situation amongst road-side vendors in the Solomon Islands, further suggesting that road-side vendors might misreport their level of sourcing from the municipal market. While socio-cultural resistors may be shaping road-side vendor behaviour, a possible more contemporary explanation is increased regulation and enforcement of trading permits of road-side vendors in Tonga.

Farm value chains that sustain South Pacific horticultural food systems are poorly understood. There is a common assumption that Pacific horticultural market supply is simply a composite of the spatial distribution of commercially active farms and transient market trading by semi-subsidence farming households [20,21]. While production-driven supply is an obvious dominant factor, the potential additional role vendors have in shaping market supply is rarely considered. It is logical to assume that semi-subsidence and small-scale farm value chains exhibit a high degree of coordination over market supply, creating an integrated and possibly closed loop chain. More commercial farm enterprise supply is likely to be far less vertically integrated. In an effort to mitigate 
against elevated postharvest loss, most market vendors in Tonga report regulating market supply to match anticipate daily consumer demand. The implication is that the majority of vendors in Tonga have a level of control over the volume of product entering the market. What is unclear is whether this influence further extends to the type of product being sourced and the level of farmer participation in the market. While complex family and social networks are known to exist within Pacific market value chains [14,24-27], power structures within Tonga's horticultural value chains and the underlying drivers and determinants are not clear and clearly warrant further investigation.

While consumer access to fresh fruit and vegetables was not implicitly assessed in this study, given a relatively decentralised market system, particularly on Tongatapu Island, high levels of private vehicle ownership [13], short intra-island transport, and supplement supply through subsistence farming and communal sharing, it would be reasonable to assume a relatively high level of physical access. What remains unclear are the potential economic resistors to accessibility, associated with product pricing, volume and the diversity of crops available. Moreover, is there any spatial or temporal disparity between urban and rural-based fruit and vegetable vendors in terms of product price, volume and diversity?

Horticultural postharvest loss in the municipal and road-side market network in Tonga was very low $(1.4 \%$ to $5.3 \%)$. In other South Pacific municipal and road-side markets, loss is commonly $10 \%$ to $12 \%$ [16-18], with much higher levels of postharvest loss regularly reported in Sub-Saharan African [28,29], the Indian subcontinent [30,31] and southeast Asia [32,33]. With the postharvest-enabling environment in Tonga encompassing smallholder and semi-subsistence farms, no cool chain, vendors operating with limited access to postharvest infrastructure, this low level of postharvest loss would seem to be at odds with the apparent likely risk factors. However, when the Tonga horticultural food system is considered in light of Tonga's very short transport distances (often less than $25 \mathrm{~km}$ ), limited inter-island trade, comparatively small traded volume (approximately $25 \%$ of produce is transported to market by private car), rapid market throughput (1 to 2 days), and the dominance of semi-perishable root crops, this apparent disparity is more easily reconciled. It is important to highlight that the amount of loss reported in this study excludes pre-harvest loss, on-farm postharvest loss due to sorting and grading, and potential loss at the consumer end of the chain, such that the whole-of-chain horticultural loss in Tonga is likely to be higher.

While levels of postharvest loss within Tonga's horticulture market and distribution system were low, there were sporadic incidences of high loss, with the road-side market vendor network particularly vulnerable. Individual vendor susceptibility to loss in Tonga is thought to reflect the type of crop being traded and chain-specific practice. Access to postharvest infrastructure, an obvious point of difference between municipal and road-side vendors, is not thought to play a major role. Road-side vendors incurring high levels of loss were often located adjacent to vendors with comparable infrastructure but little or no loss. There was also little difference in the incidence loss between fruit, vegetable and root crops value chains. Vendor vulnerability to elevate postharvest loss was more likely to reflect the type of crop being traded, specifically crops requiring prolonged market storage due to in-market ripening (i.e., tomato and banana) or possible slow market throughput (i.e., taro and watermelon). Vendor vulnerability to loss was further influenced by their capacity to regulate their market supply, and the level of on-farm grading undertaken within the chain.

Counterintuitively, low levels of postharvest loss within Tonga's horticultural market and distribution system maybe grounds for concern, especially in the context of the agriculture-nutrition nexus. Vendor upregulating and restricting market supply, while apparent effective mitigate strategies against loss, have the potential to impact on the volume of product entering the market. In an environment where donors are focused on increasing domestic production to improve accessibility of fresh fruit and vegetables in Tonga in support of pro-health benefits, vendor-regulated market supply may be an overlooked resistor within the horticulture fresh food systems. The other concern relates to a possible lack of resilience within the horticultural market system. While short intra-island transport distances, limited trade of highly-perishable leafy vegetables and fast market throughput 
provide a relatively low-risk postharvest environment, this may have also inadvertently created a level of complacency within the horticultural food system. Evidence of this can be seen in the apparent prevalence of prolonged on-farm storage, limited packaging, and an over reliance by vendors on supply regulation and discount-pricing interventions as opposed to more formative postharvest handling practice. This may, in part, explain why sporadic incidences of postharvest loss in Tonga were often associated with atypically high levels of loss. Rather than view low levels of postharvest horticultural loss in Tonga as indicative of value chain efficiency, a possibly more appropriate appraisal is that of a relatively low-risk postharvest environment. The implication is that if Tonga's horticultural markets are placed under stress for any reason, due to restricted supply or consumer access, this may result in disproportionally high levels of resultant postharvest loss.

\section{Conclusions}

Tonga has a relatively decentralised horticultural market network due to a network of road-side vendors, which afford few structural resistors in terms of consumer accessibility to fresh fruits and vegetables. While Tonga's horticultural markets experience little postharvest loss, this is thought to reflect a comparatively low postharvest risk environment, rather than a level of value chain operational efficiency. Short transport distance, limited horticultural supply, a prevalence of root crop value chains and corresponding little trade of perishable leafy vegetables, and rapid market throughput collectively reduce a vendor's likelihood of incurring loss and possibly compensate for poor postharvest practice and limited infrastructure. This low postharvest loss-enabling environment may have wide implications. With the majority of vendors regulating market supply in an attempt to mitigate against postharvest loss, this could be adversely limiting market supply volumes. If this is the case, vendor-regulated market supply might be partially undermining wider efforts to improve consumer access to affordable fresh fruits and vegetables. With few intrinsic postharvest risk factors within the chain, existing vendor practice and operations may be more vulnerable to external shocks. Potential changes in the market system in Tonga, necessitating prolonged transport or market storage (i.e., adverse weather, or increased inter-island trade, or export), the inclusion of more perishable crops (i.e., increased domestic production or importation of leafy vegetables), or a re-centralisation of the market structure (i.e., potential closure of road-side markets) may result in disproportionally higher levels of postharvest loss.

In the context of Tonga's agriculture-nutrition nexus, road-side market vendors provide an important contribution in terms of enhanced consumer accessibility to fresh fruits and vegetables. Strategies to better support road-side vendors, particularly in regards to reducing the risk of sporadic atypical high loss, warrant further investigation. Counterintuitively, low levels of vendor postharvest loss in Tonga may actually be of concern, highlighting the need to also understand the enabling environment and contributory chain practices.

Author Contributions: Conceptualization, S.J.R.U. and S.P.; methodology, S.J.R.U. and S.P.; investigation, S.J.R.U. and enumerators associated with MORDI; statistical analysis, Y.Z.; writing-original draft preparation, S.J.R.U., S.B., Y.Z., and S.P.; writing-review and editing, S.J.R.U., Y.Z., S.P. and S.B. All authors have read and agreed to the published version of the manuscript.

Funding: This research was funded by the Food and Agriculture Organisation of the United Nations, and Australian Centre for Pacific Island Studies, University of the Sunshine Coast, Australia.

Acknowledgments: We would like to express our sincere appreciation for the invaluable assistance and support provided by enumerators from MORDI, Rhiannon Underhill for a preliminary manuscript review, and the numerous Tongan smallholder farmers and vendors who provided their time and input in support of this study.

Conflicts of Interest: The authors declare no conflict of interest. The funders had no role in the design of the study; in the collection, analyses, or interpretation of data; in the writing of the manuscript, or in the decision to publish the results. 


\section{References}

1. Evans, M.; Sinclair, R.C.; Fusimalohi, C.; Liava'a, V. Diet, health and the nutrition transition: Some impacts of economic and socio-economic factors on food consumption patterns in the Kingdom of Tonga. Pac. Health Dialog 2002, 9, 309-315.

2. Evans, M.; Sinclair, R.C.; Fusimalohi, C.; Laiva'a, V.; Freeman, M. Consumption of traditional versus imported foods in Tonga: Implications for programs designed to reduce diet-related non-communicable diseases in developing countries. Ecol. Food Nutr. 2003, 42, 153-176. [CrossRef]

3. Ma'asi, L.; Francis, J.A. The Agriculture-Nutrition-Income Nexus in Tonga. Available online: https: //cgspace.cgiar.org/handle/10568/106670 (accessed on 17 March 2020).

4. $\quad$ Lin, S.; Hufanga, S.; Linhart, C.; Morrell, S.; Taylor, R.; Magliano, D.J.; Zimmet, P. Diabetes and obesity trends in Tonga over 40 years. Asia Pac. J. Public Health 2016, 28, 475-485. [CrossRef] [PubMed]

5. Ogurtsova, K.; da Rocha Fernandes, J.D.; Huang, Y.; Linnenkamp, U.; Guariguata, L.; Cho, N.H.; Cavan, D.; Shaw, J.E.; Makaroff, L.E. IDF Diabetes Atlas: Global estimates for the prevalence of diabetes for 2015 and 2040. Diabetes Res. Clin. Pract. 2017, 128, 40-50. [CrossRef] [PubMed]

6. Savage, A.; McIver, L.; Schubert, L. The nexus of climate change, food and nutrition security and diet-related non-communicable diseases in Pacific Island Countries and Territories. Clim. Dev. 2020, 12, 120-133. [CrossRef]

7. National Strategy for Prevention and Control of Non-Communicable Diseases 2015-2020. Available online: https://www.dfat.gov.au/sites/default/files/tonga-national-non-communicable-disease-strategy-201520.pdf (accessed on 25 March 2020).

8. Ika, E.S. Tonga Domestic Market Study Using the Domestic Market Survey Report to Investigate Selected Policy Issues; FAO Technical Report; FAO: Apia, Samoa, 2011. Available online: http://www.fao.org/3/a-an419e.pdf (accessed on 17 March 2020).

9. Underhill, S.J.R.; Singh-Peterson, L. Improving non-communicable disease remediation outcomes in Tonga: The importance of domestic fruit production systems: An analysis. J. Agric. Rural Dev. Trop. Subtrop. 2017, 118, 91-103.

10. Sio-Ki-Sia Fonua, F. A Learning Journey to the Kingdom of Tonga: Accelerating Transformative Change in Nutrition-Sensitive Value Chains in Pacific Islands: Promoting Nutritious Food Systems in the Pacific Islands. Available online: https://books.google.com.au/books?hl=en\&lr=\&id=V2CqDwAAQBAJ\&oi=fnd\&pg=PP1\& $\mathrm{dq}=$ nutritional+sensitive+food+system +tonga\&ots=9THrV8I2zf\&sig=yG9k0ikJLR741hgFo4_P76w5P9w (accessed on 12 March 2020).

11. Tonga Department of Statistic. Tonga Household Income and Expenditure Survey 2009. Available online: http://sdd.spc.int/collection/2009-household-income-and-expenditure-survey-collection-tonga (accessed on 23 March 2020).

12. Tonga Department of Statistic. Tonga Household Income and Expenditure Survey 2015/2016. Available online: https://sdd.spc.int/news/2018/02/02/tonga-household-income-and-expenditure-survey-20152016report (accessed on 23 March 2020).

13. Lolohea, S.; Demmke, A. Tonga 2006 Census of Population and Housing Volume 2: Analytical Report; Secretariat of the Pacific Community: New Caledonia, France, 2008; pp. 1-163.

14. Hau' ofa, E. Corned Beef and Tapioca: A Report on the Food Distribution Systems in Tonga; The Australian National University Press Monograph 19: Canberra, Australia, 1979; pp. 85-157.

15. Tonga Statistic Department. Available online: https://tongastats.gov.to/statistics/social-statistics (accessed on 11 March 2020).

16. Underhill, S.J.R.; Kumar, S. Quantifying horticulture postharvest wastage in three municipal fruit and vegetable markets in Fiji. Int. J. Postharvest Technol. Innov. 2014, 4, 251-261. [CrossRef]

17. Underhill, S.J.R.; Zhou, Y.; Sherzad, S.; Singh-Peterson, L.; Tagoai, S.M. Horticultural postharvest loss in municipal fruit and vegetable markets in Samoa. Food Secur. 2017, 9, 1373-1383. [CrossRef]

18. Underhill, S.J.R.; Joshua, L.; Zhou, Y. A preliminary assessment of horticultural postharvest market loss in the Solomon Islands. Horticulturae 2019, 5, 5. [CrossRef]

19. Taulealea, S. A Feasibility Study for Developing a Marketing Centre at the Navuso Agricultural School in Fiji. Master's Thesis, University of Wyoming, Laramie, WY, USA, 2005; pp. 1-456. 
20. Georgeou, N.; Hawksley, C. Challenges for sustainable communities in Solomon Islands: Food production, market sale and livelihoods on Savo Island. J. Multidiscip. Int. Stud. 2017, 14, 67-86. [CrossRef]

21. Georgeou, N.; Hawksley, C.; Monks, J. Food security in Solomon Islands: Preliminary results from a survey of the Honiara Central Market. J. Interdiscip. Res. 2018, 2, 53-70.

22. Apa, T.; Boto, I.; Addison, C.; Jejov, E.; Senou, O. Whole-Family Approach to Agricultural Market Success. 2019. Available online: https://cgspace.cgiar.org/bitstream/handle/10568/101284/2078_PDF.pdf?sequence=1\& isAllowed $=\mathrm{y}$ (accessed on 14 May 2020).

23. Georgeou, N.; Hawksley, C.; Monks, J.; Ki'i, M. Food security and asset creation in Solomon Islands: Gender and the political economy of agricultural production for Honiara central market. J. Multidisc. Int. Stud. 2019, 16, 101-118. [CrossRef]

24. Gewertz, D. Tit for Tat: Barter markets in the middle Sepik. Anthropol. Q. 1978, 51, 37-44. [CrossRef]

25. Carrier, J.G.; Carrier, A.H. Wage, Trade and Exchange in Melanesia: A Manus Society in the Modern State; University of California Press: Berkeley, CA, USA, 1989; pp. 1-257.

26. Bennediktsson, K. Food markets in the eastern highlands, Papua New Guinea: Actors, power and rural development geography. Geogr. Ann. Ser. B 1998, 80, 159-172. [CrossRef]

27. Kumar, S. Postharvest Handling Practices and Losses of Tomato along Value Chains in Fiji. Ph.D. Thesis, University of the South Pacific, Suva, Fiji, 2017; pp. 1-201.

28. Kitinoja, L.; AlHassan, H.Y. Identification of appropriate postharvest technologies for small scale horticultural farmers and marketers in Sub-Saharan Africa and South Asia-Part 1. Postharvest losses and quality assessments. Acta Hortic. 2010, 934, 31-40. [CrossRef]

29. Affognon, H.; Mutungi, C.; Sanginga, P.; Borgemeister, C. Unpacking postharvest losses in sub-Saharan Africa: A meta-analysis. World Dev. 2015, 66, 49-68. [CrossRef]

30. Aujla, K.M.; Shah, N.A.; Ishaq, M.; Fraooq, A. Post-harvest losses and marketing of grapes in Pakistan. Sarhad J. Agric. 2011, 27, 485-490.

31. Ahmed, U.I.; Ying, L.; Mushtaq, K.; Bashir, M.K. An econometric estimation of post-harvest losses of kinnow in Pakistan. Int. J. Econ. Commer. Manag. 2015, 3, 373-383.

32. Ladaniya, M.S. Postharvest management of citrus fruit in south Asian countries. Acta Hortic. 2015, 1065, 1669-1676. [CrossRef]

33. Gunasekera, D.; Parsons, H.; Smith, M. Post-harvest loss reduction in Asia-Pacific developing economies. J. Agribus. Dev. Emerg. Econ. 2017, 7, 303-317. [CrossRef] 